\title{
From 3D Seismic to 3D Reservoir Deterministic Model Thanks to Logging Data: the Case Study of a Near Surface Heterogeneous Aquifer
}

\author{
J.L. Mari ${ }^{1}$, G. Porel ${ }^{2}$ and B. Bourbiaux' \\ 1 Institut français du pétrole, IFP, 1-4 avenue de Bois-Préau, 92852 Rueil-Malmaison Cedex - France \\ 2 Université de Poitiers, UMR 6532 Hydrasa, Poitiers - France \\ e-mail: j-luc.mari@ifp.fr - gilles.porel@univ-poitiers.fr - bernard.bourbiaux@ifp.fr
}

\begin{abstract}
Résumé - Construction d'un modèle déterministe de réservoir associé à un aquifère peu profond à l'aide de la sismique 3D et des diagraphies - Différentes acquisitions sismiques ont été réalisées sur le site hydrologique expérimental de Poitiers (France). Ce papier montre comment la sismique 3D peut être mise en œuvre et traitée pour décrire un aquifère hétérogène proche de la surface. Le dispositif d'acquisition a été choisi pour obtenir à la fois une imagerie par réfraction et par réflexion. La sismique réfraction a permis d'obtenir une image en profondeur du toit de l'aquifère carbonaté et a mis en évidence les directions principales (N90 et N50) de couloirs de fractures. Ces deux directions ont été retenues pour implanter deux puits déviés $\mathrm{C} 3$ et $\mathrm{C} 4$. La sismique réflexion a permis d'obtenir un bloc de vitesse 3D en profondeur. Le bloc de vitesse montre la forte hétérogénéité du réservoir aquifère et confirme les orientations principales des structures mises en évidence par réfraction. Les zones à faible vitesse correspondent à des zones à forte conductivité hydraulique. Dans le but de quantifier la porosité des différents niveaux aquifères, les vitesses sismiques ont été converties en résistivité, en utilisant la relation empirique proposée par Faust (1953) [Geophysics 18, 271-288] calibrée sur des logs de résistivité enregistrés dans 11 puits du site. Le bloc de résistivité, converti en porosité en utilisant la loi d'Archie (1942) [Petrol. Technol. 146, 54-62], a permis d'identifier 3 niveaux producteurs d'eau : un niveau supérieur à 35-40 $\mathrm{m}$, un niveau intermédiaire à 85-87 m, un niveau inférieur à 110-115 m. Le niveau intermédiaire est composé de corps ayant des porosités supérieures à $30 \%$. Ces corps représentent la partie karstique du réservoir. La sismique 3D très haute résolution a permis d'obtenir un bloc $3 \mathrm{D}$ de porosité qui représente un modèle déterministe de réservoir. À l'issue d'une calibration plus avancée, ce modèle de réservoir pourrait être utilisé pour réaliser des simulations d'écoulement.
\end{abstract}

\footnotetext{
Abstract - From 3D Seismic to 3D Reservoir Deterministic Model Thanks to Logging Data: the Case Study of a Near Surface Heterogeneous Aquifer-Different surface seismic surveys have been recorded on an experimental hydrogeological site that has been developed for several years near Poitiers (France). The paper shows how 3D seismic imaging can be used to describe the near-surface heterogeneous aquifer. The acquisition spread is designed to perform both $3 D$ refraction and reflection seismic surveying. Refraction survey enables us to obtain a $3 D$ image in depth of a low velocity superficial zone contrasting with the underlying water - bearing carbonates. Refraction survey shows the main orientations (N90 and N50) of fracture corridors. These two directions have been selected as the
} 
drilling azimuths of two deviated wells C3 and C4. Reflection survey enables us to generate a 3D seismic pseudo velocity block in depth. The 3D seismic pseudo velocity block shows the large heterogeneity of the aquifer reservoir in the horizontal and vertical planes, and confirms the main structural orientations (N90 and N50) identified by the refraction survey. The low velocity areas correspond to high hydraulic conductivity. In order to quantify the porosity of the different productive layers of the aquifer, the interval seismic velocities have been converted in resistivity. For that purpose, the empirical relationship between seismic velocity and true formation resistivity proposed by Faust (1953) [Geophysics 18, 271-288] has been used. The 3D resistivity block is converted in porosity, by using the Archie law (1942) [Petrol. Technol. 146, 54-62]. The 3D seismic pseudo porosity block allows us to identify three different water productive layers: an upper layer at 35-40 m depth, an intermediate layer at 85-87 m depth and a lower layer at 110-115 m. The intermediate layer is composed of bodies having a porosity larger than $30 \%$. These bodies represent the most karstic part of the reservoir. The very high resolution seismic surveying has led to obtain a 3D porosity seismic block which represents a deterministic high resolution reservoir model. After further calibration, that reservoir model could be used for flow simulation.

\section{INTRODUCTION}

Many underground aquifers were developed as experimental sites during the past decade. These sites are designed for in-situ measurements and calibration of flow, transport and/or reactions in underground reservoirs that are heterogeneous by nature.

The University of Poitiers (France) has a Hydrogeological Experimental Site (HES) built nearby the Campus for the sole purpose of providing facilities to develop long-term monitoring and experiments for a better understanding of flow and transfers in fractured rocks (Bernard et al., 2006; Kaczmaryk and Delay, 2007; Bourbiaux et al., 2007). The concerned aquifer, 20 to $130 \mathrm{~m}$ in depth, consists of tight karstic carbonates of Middle Jurassic age. It lies on the borderline, named the "Poitou threshold", between the Paris and the Aquitaine sedimentary basins (Fig. 1). The Hydrogeological Experimental Site (HES) covers an area of
12 hectares over which 35 wells were drilled to a depth of $120 \mathrm{~m}$ (Fig. 1). Hydrogeological investigations show that maximum pumping rates vary from well to well and range from 5 to $150 \mathrm{~m}^{3} / \mathrm{h}$. The top of the reservoir was initially flat and horizontal, 150 millions years ago, but has been eroded and weathered since, during Cretaceous and Tertiary ages. It is shaped today's as hollows and bumps with a magnitude reaching up to $20 \mathrm{~m}$. According to Burbaud-Vergnaud (1987), the fractures are almost vertical and to quantify their density, 3 vertical or tilted core-sampled boreholes have been drilled.

The present publication shows the benefit of using 3D seismic surveys to describe the near surface aquifer, and to detect and identify the water flow paths. The acquisition of usable seismic data is particularly difficult for shallow reservoirs underlying a thick weathered zone, such as the aquifer studied here. In the paper, we propose to show how both 3D refraction and reflection seismic surveying can be used to
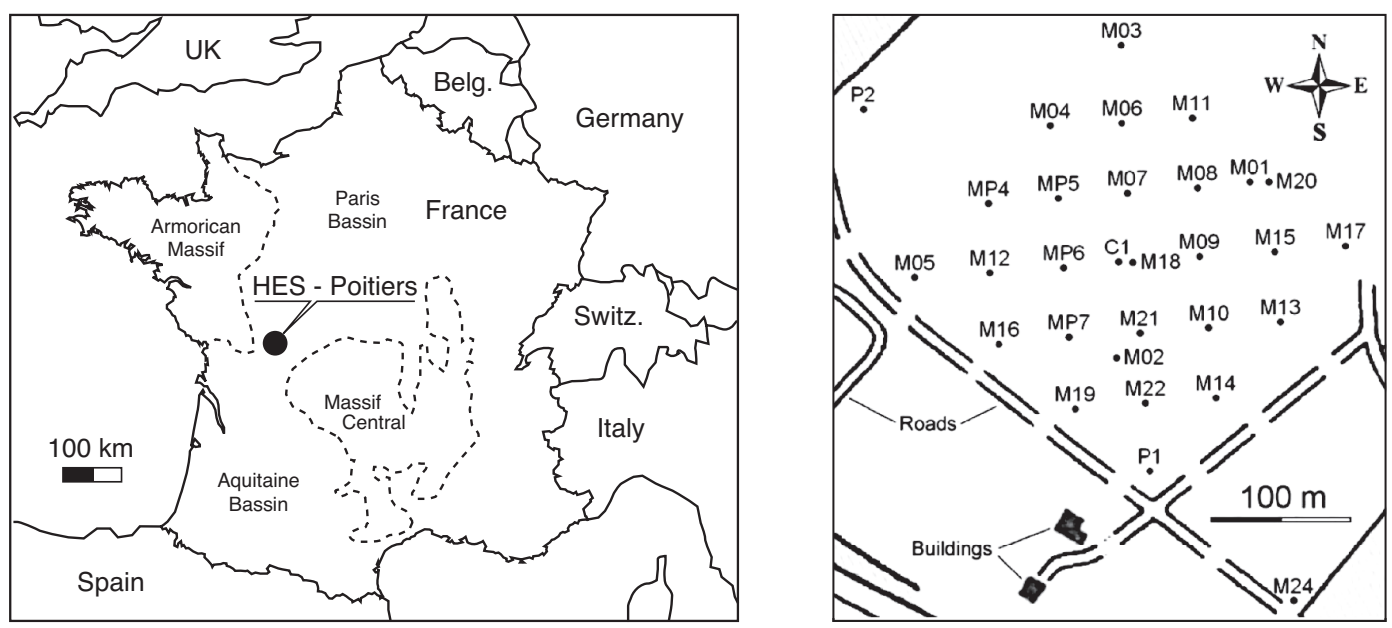

Figure 1

Hydro-geological experimental site in Poitiers: site map and well location. 
extract structural information and to describe the near-surface heterogeneous aquifer. We show the benefit of combining both 3D seismic surveying and logging data (acoustic logs and resistivity logs) to transform the $3 \mathrm{D}$ seismic data into a 3D high resolution petrophysical model of the reservoir.

\section{SEISMIC SURVEYING}

Different surface seismic surveys were attempted with different acquisition schemes. These preliminary studies (Mari and Porel, 2007) lead us to select the following spreads for 3D imaging. A detonating impulse source has been selected to record high frequency data. To preserve the high frequency content of the data and to have an accurate picking of the refracted wave, a single geophone per trace has been used. To avoid any spatial aliasing, a $5 \mathrm{~m}$ distance between two adjacent geophones has been selected. Due to the limitations of the area, the length of the seismic line could not exceed $250 \mathrm{~m}$, in the in-line direction. Consequently, a 48 channel recorder was used. In the cross line direction, the extension of the area does not exceed $300 \mathrm{~m}$. As a result, 21 receiver lines have been implemented, with a $15 \mathrm{~m}$ distance between adjacent lines. For the refraction survey, a direct shot and a reverse shot have been recorded per receiver line. For the reflection survey, 3 shot points in the cross line direction have been fired at distances of 40,50 and $60 \mathrm{~m}$ from the receiver line under consideration. The range of offsets has been selected to optimize the quality of the seismic image over the reservoir depth interval, between 40 and $130 \mathrm{~m}$. The
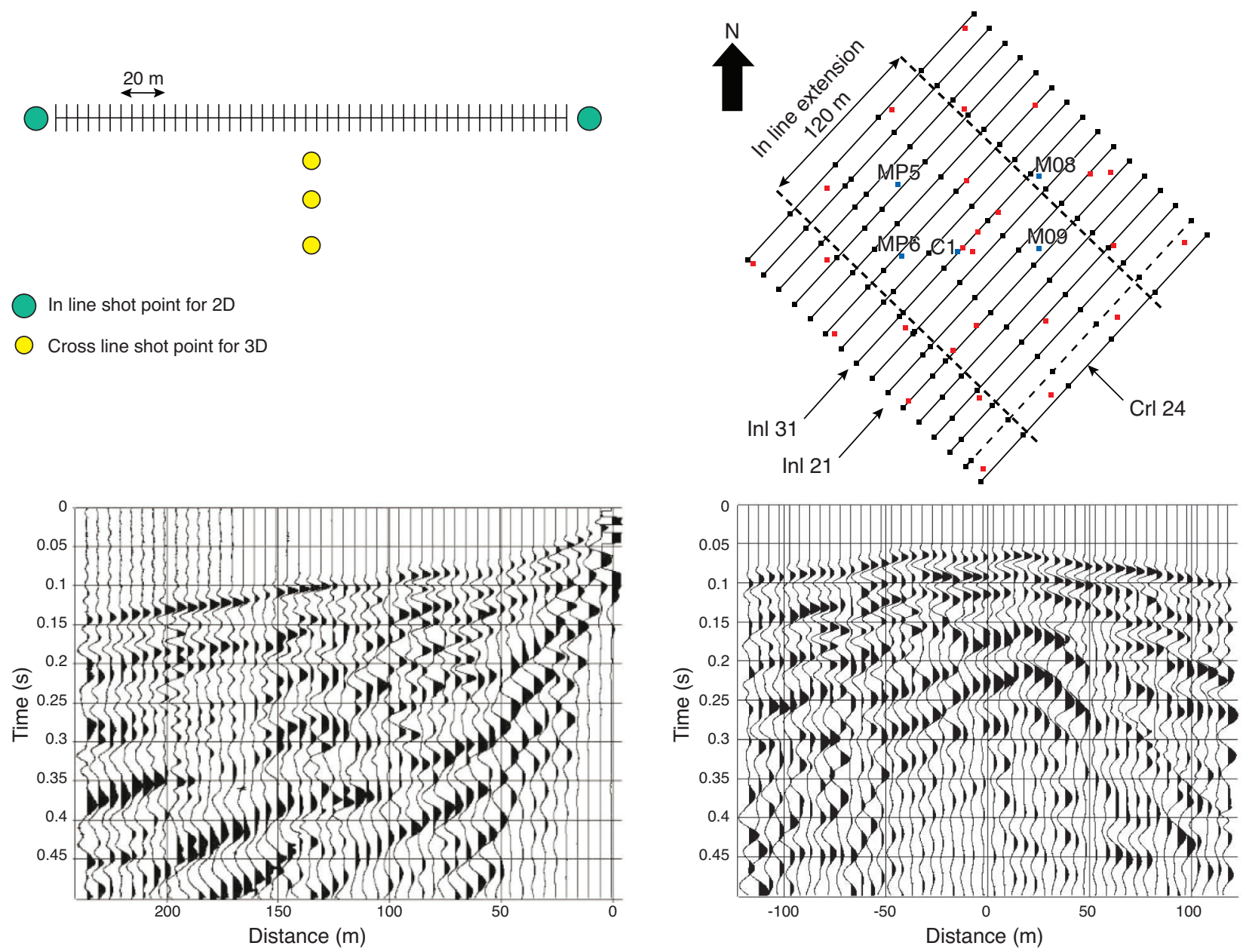

Figure 2

Seismic spreads and field examples of 2D and 3D shot points. Top left: seismic spread for 2D and 3D seismic acquisition.

Top right: seismic line implementation and well locations (red points). The distance between 2 adjacent lines is $15 \mathrm{~m}$. The doted lines indicate the lateral extension of the 3D seismic block. The in line seismic sections ("Inl 21" and "Inl 31") and the cross line seismic section ("Crl 24") are located on the map.

Bottom left: example of 2D shot point for refraction survey. Bottom right: example of 3D shot point (cross spread). 
minimum offset distance has been chosen equal to $40 \mathrm{~m}$ to reduce the influence of the surface waves. The time sampling interval is $0.25 \mathrm{~ms}$ and the recording length is $0.5 \mathrm{~s}$. Figure 2 shows the selected seismic spreads and the map locating the seismic lines. Full waveform acoustic logs have been recorded in 5 wells (C1, MP5, MP6, M08, M09). In well C1, a vertical seismic profile (VSP) has been recorded. Figure 2 also shows examples of shot points for refraction survey and 3D reflection survey (cross spread). Refraction seismic uses in-line shots for 2D profiles along geophone lines. Reflection seismic is based on cross-line shots for 3D acquisition purpose.

\subsection{Refraction Seismic Surveying}

Refraction seismic surveying, described in detail by Mari and Porel (2007), has been used to map the irregular shape of the top of the karstic reservoir. The Hagedoorn's Plus-Minus method (1959) has been used to compute a delay map (Fig. 3, top left) which has been converted into a depth map (Fig. 3, top right). An omni-directional variogram is computed (Fig. 3, bottom left). The variogram model is composed of a nugget effect, a cubic structure with a range of $55 \mathrm{~m}$ and a long-scale spherical structure with a range of $145 \mathrm{~m}$. Finally, a kriging with the model so defined and a filtering of the nugget effect (random acquisition noise) are performed to obtain the filtered WZ depth map. Factorial kriging is used to filter both the nugget effect and the smallscale structures (with a range of $55 \mathrm{~m}$ ) in order to obtain a map showing the large-scale structures alone. Figure 3 (bottom right) shows the resulting depth map of the weathered zone after filtering the small-scale structures. That is, the interpretation of seismic refraction data allowed to map the
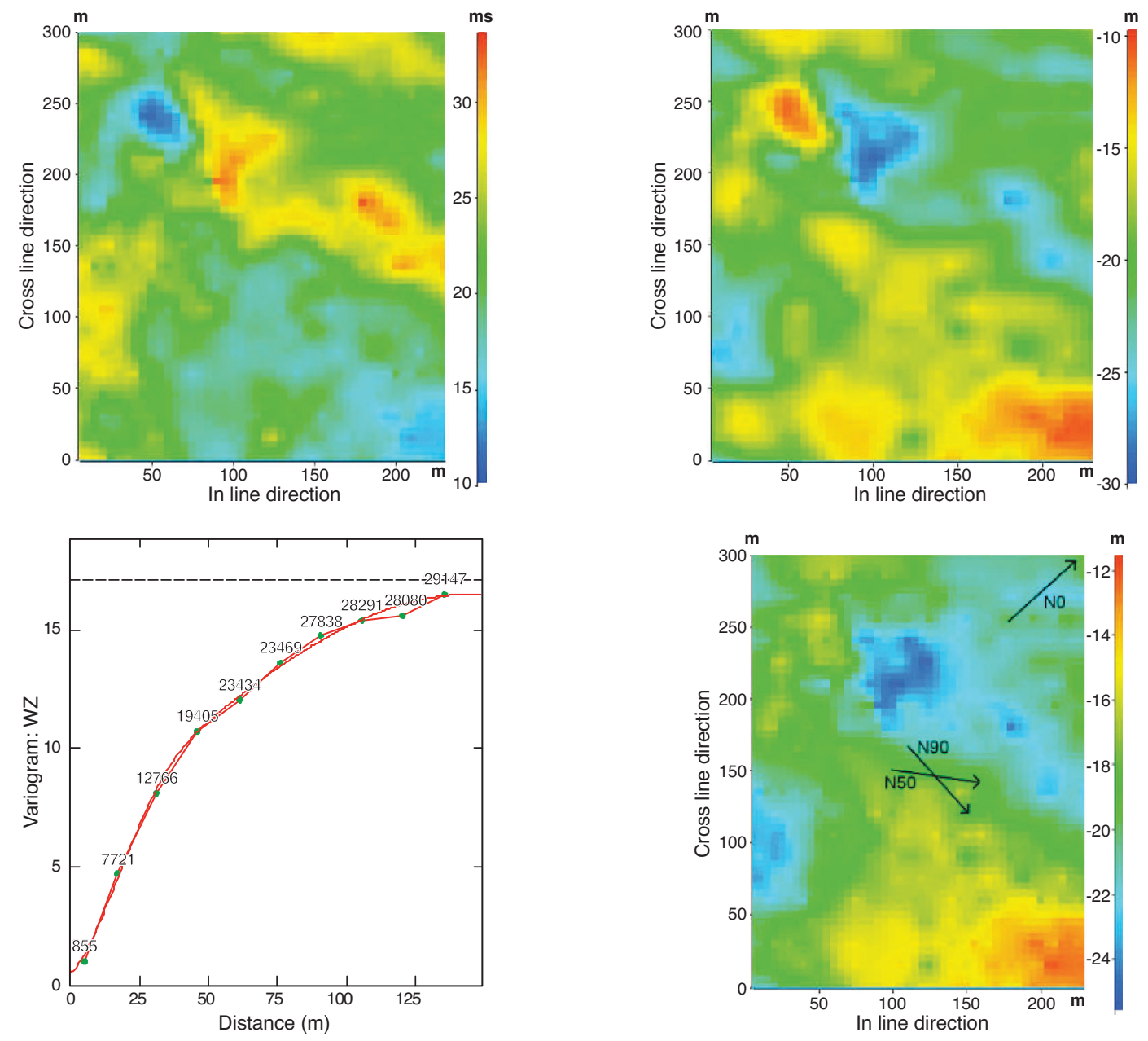

Figure 3

Refraction survey.

Top left: delay map (ms). Top right: WZ depth map (m).

Bottom left: experimental omnidirectional variogram and modeling.

Bottom right: WZ depth map after filtering of the small scale structures by factorial kringing based on omnidirectional variogram and orientation of the geological structures. 
top of the limestone reservoir. The map also enables us to identify the directions of the geological structure at the site scale. Taking the North as the origin of azimuths (arrow NO in Fig. 3), the main structure orientation is found to be N90E. A secondary orientation, N50E, can also be identified. These two preferential directions, drawn from the geostatistical processing of geophysical data coincide with the main fracture directions measured by Burbaud-Vergneaud (1987) in the vicinity of Poitiers. Only the so-called South Brittany direction (oriented N135) is not visible since it corresponds to major features found at intervals ranging from several hundred meters to a few kilometers. Data from refracted seismic revealed very valuable to confirm the expected directions of the main fracture families, and to select the trajectories of two boreholes, $\mathrm{C} 3$ and $\mathrm{C} 4$. The $\mathrm{C} 3$ borehole was drilled in the N90E direction whereas the $\mathrm{C} 4$ borehole was drilled in the N45E direction.

\subsection{Reflection Seismic Surveying}

The studied field case (Mari and Porel, 2007) has shown the possibility of recording very light $3 \mathrm{D}$ high resolution seismic data for an accurate description of the near surface heterogeneous aquifer.

The field equipment is reduced to a 48 -active channels recorder, a template composed of 48 vertical geophones and small charges of dynamite ( $25 \mathrm{~g}$ per shot point) at each source point. 20 templates have been implemented.
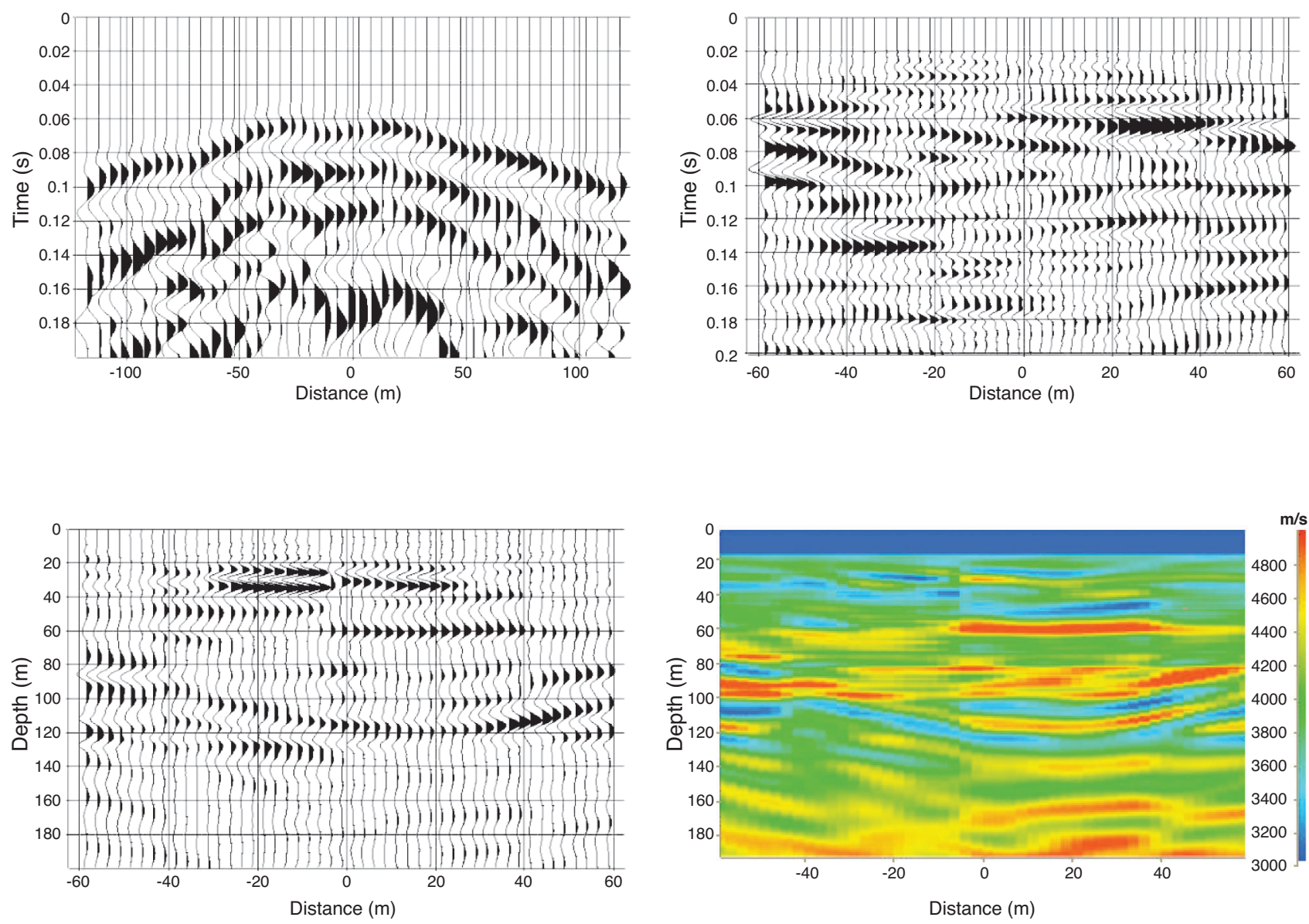

Figure 4

3D Reflection surveying: processing sequence of geophone line 11 with $60 \mathrm{~m}$ source offset. (denoted "Inl 31" and located on the map shown in Fig. 2).

Top left: raw shot point (cross spread) after amplitude recovery.

Top right: time section after deconvolution, wave field separation and NMO corrections. Bottom left: depth section after deconvolution and depth tying at well C1.

Bottom right: depth pseudo velocity section. 
A template is a single receiver line composed of 48 geophones with a $5 \mathrm{~m}$ distance between two adjacent geophones. For each template location, 3 shot points (cross spread) are recorded with offsets ranging between 40 to $60 \mathrm{~m}$. Figure 4 (top left) shows the shot point (cross spread) obtained with the template (or line) 11 with a $60 \mathrm{~m}$ source offset. The cross line move up (distance between 2 adjacent templates in the cross line direction) is $15 \mathrm{~m}$. The geometry of acquisition leads us to obtain a single fold 3D block with a $2.5 \mathrm{~m} \times 5 \mathrm{~m}$ bin surface area. The 3D block is composed of 60 in line sections and 48 cross line sections. Due to the geometry of acquisition, the shot point recorded on geophone line 11 with a $60 \mathrm{~m}$ source offset provides the image of the in-line section 31 situated at a cross-line distance of $120 \mathrm{~m}$. (Inl 31).

The complete processing sequence has been described in detail by Mari and Porel (2007). It includes amplitude recovery, deconvolution, wave separation and normal move out corrections. The velocity model used to perform the normal move out corrections has been computed from the velocity versus time relationship given by the Vertical Seismic Profile (VSP) recorded in well $\mathrm{C} 1$. Each shot point (cross spread) has been processed independently to obtain a single-fold zero-offset time-section with a sampling interval of $2.5 \mathrm{~m}$ (half the distance between 2 adjacent geophones) in the in line direction. The VSP time versus depth law has also been used to convert the time sections into depth sections with a $0.5 \mathrm{~m}$ depth sampling interval. These 60 single-fold vertical sections have been merged to create a $3 \mathrm{D}$ block. The width of the block in the in line direction equals $120 \mathrm{~m}$ and $300 \mathrm{~m}$ in the cross line direction. The abscissa zero indicates the location of the source line. The abscissa of the reflecting points varies between $-60 \mathrm{~m}$ and $+60 \mathrm{~m}$ in the in line direction, the distance between two reflecting points equals $2.5 \mathrm{~m}$. The depth sections have been de-convolved in order to increase the vertical resolution. The de-convolved depth sections have been then integrated with respect to depth to transform the amplitude block into a 3D pseudo-velocity block in depth, using velocity functions (acoustic logs recorded at wells C1, MP5, MP6, M08, M09) as constraints. Figure 4 shows the complete processing sequence of geophone line 11 obtained with a $60 \mathrm{~m}$ source offset. To conclude, the previously-described processing sequence resulted in a fairly-high resolution velocity model of the studied reservoir, with more than 500000 cells of $2.5 \mathrm{~m} \times 5 \mathrm{~m} \times 0.5 \mathrm{~m}$ in size. The vertical resolution is in the order of 1 or $2 \mathrm{~m}$.

\section{FROM 3D SEISMIC TO 3D POROSITY}

In the area covered by the 3D seismic surveying, 11 wells (MP4, MP6, M21, M14, MP5, M18, M10, M04, M07, M09 and M13, with location shown in Fig. 7) have been drilled. The wells are regularly spaced $(\sim 50 \mathrm{~m})$ and used to perform many hydraulic tests (interference pumping and slugs).
Interference testing allows to grasp the hydrodynamic behavior at the site scale but cannot give a detailed image of the flow paths between wells, even if pressure transients may differ from one observation well to another. In the wells, several logs have been recorded (electrical and gamma ray logs).

The homogeneous spatial distribution of wells, in which resistivity logs have been recorded, leads us to select a method based on electrical measurements to quantify the $3 \mathrm{D}$ porosity distribution within that aquifer. The seismic interval velocity-to-porosity conversion was performed in two steps (Mari and Porel, 2008):

- from 3D interval seismic velocity to 3D resistivity,

- from $3 \mathrm{D}$ resistivity to $3 \mathrm{D}$ porosity.

\subsection{From 3D Interval Seismic Velocity to 3D Resistivity}

Faust (1953) has established an empirical relationship between seismic velocity $V$, depth $Z$, and electrical resistivity measurements $R_{t}$. For a formation of a given lithology, the velocity $V$ can be written as a function of the depth $Z$ and resistivity $R_{t}$ as follows:

$$
V=C \cdot\left(Z \cdot R_{t}\right)^{1 / b}
$$

with:

- $V$ the $P$-wave velocity of the formation in $\mathrm{m} / \mathrm{s}$,

- $Z$ the depth in $\mathrm{m}$,

- $R_{t}$ the electrical resistivity in ohm.m,

- $C$ and $b$ the coefficients associated with the Faust's equation.

At each well where a long normal log has been recorded, an interval velocity log has been extracted from the 3D seismic interval velocity block. The two sets of data (resistivity and seismic velocity) have been combined to calibrate an empirical Faust's law, which has then been used as a local constraining function to transform the 3D pseudo-velocity block into a 3D pseudo-resistivity. For each well, the two coefficients, $C$ (constant coefficient) and $b$ (power law exponent), of that empirical law were determined through a leastsquare minimization of the difference between the 3D-blockextracted seismic velocities and the velocities predicted from Faust's law using the long normal resistivity log data as input. 2D distribution maps of the $C$ and $b$ values over the site could then be built from the calibrated values in each of the 11 wells, as shown in Figure 5 (top right and top left). These maps were used for the velocity-resistivity conversion of the 3D seismic block. Figure 5 (bottom) shows the results obtained at well MP6.

Figure 6 shows the pseudo-velocity and pseudo-resistivity depth sections for the in line section 21, the in line section 31 , and the cross line section 24. Figure 6 also shows the pseudovelocity and pseudo-resistivity horizontal sections at a depth 
JL Mari et al. / From 3D Seismic to 3D Reservoir Deterministic Model Thanks to Logging Data: the Case Study of a Near Surface Heterogeneous Aquifer
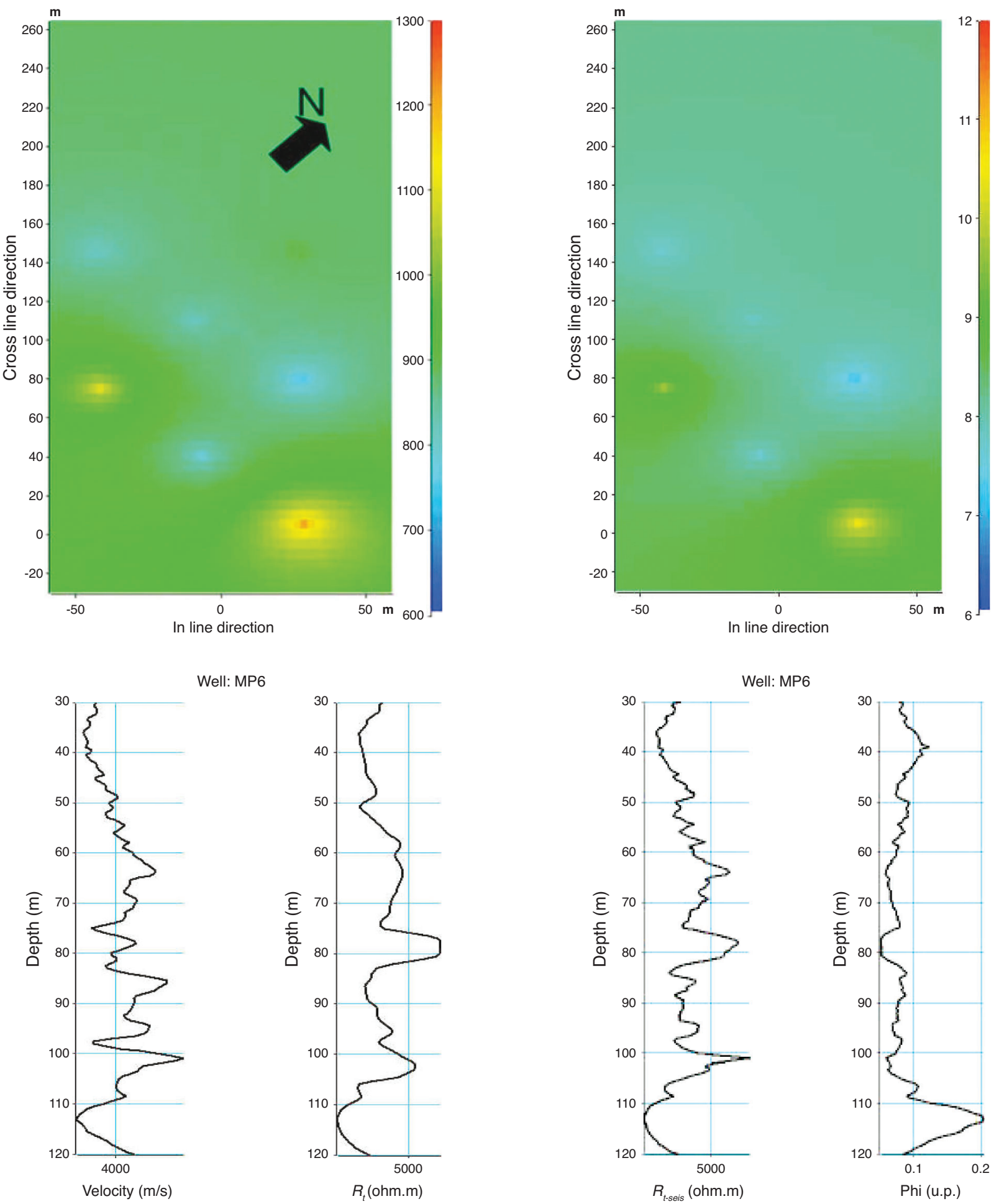

Well: MP6

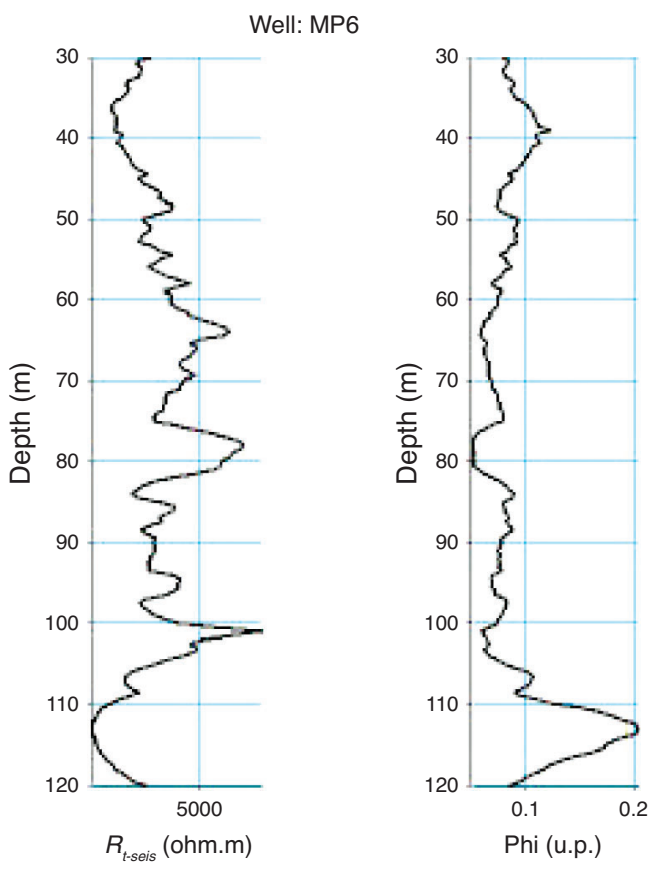

Figure 5

From seismic velocity to porosity thanks to velocity-resistivity conversion:

Top: velocity-resistivity conversion based on Faust's law maps: Top left: constant coefficient map, Top right: power law exponent map.

Bottom: example of seismic velocity-porosity conversion at well MP6:

Bottom left: comparison between seismic velocity and resistivity from long normal $\log \left(R_{t}\right)$,

Bottom right: resistivity $R_{t-\text { seis }}$ computed from seismic velocity based on Faust's law and porosity computed from $R_{t-\text { seis }}$ based on Archie's law.

The correlation coefficient between $R_{t}$ and $R_{t \text {-seis }}$ is 0.89 . 
3D block: In line resistivity and velocity seismic sections
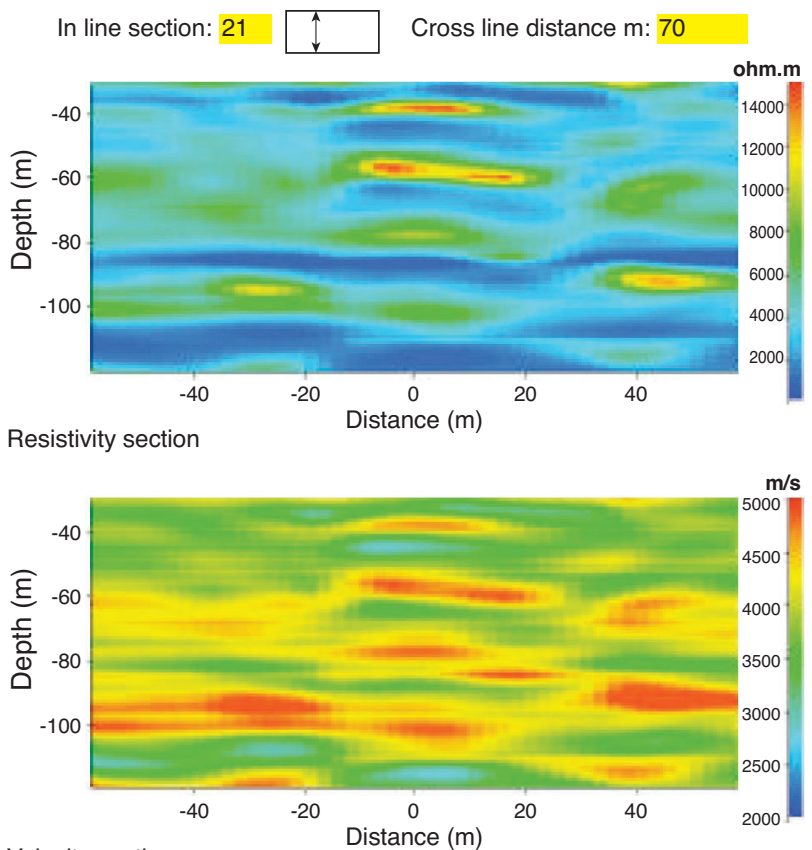

Velocity section

3D block: Cross line resistivity and velocity seismic sections

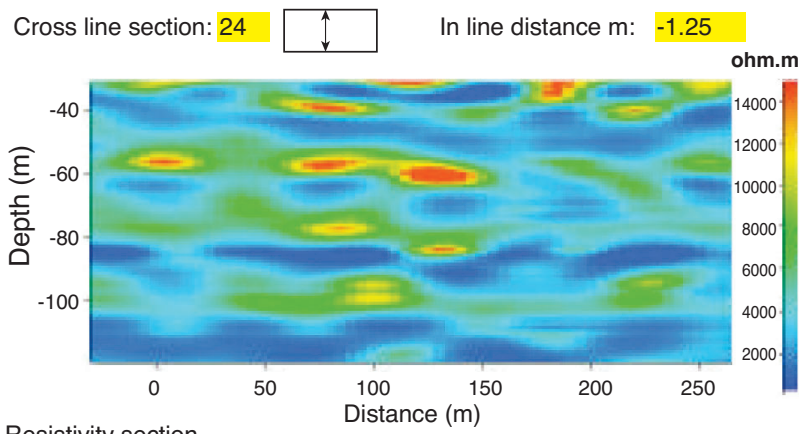

Resistivity section

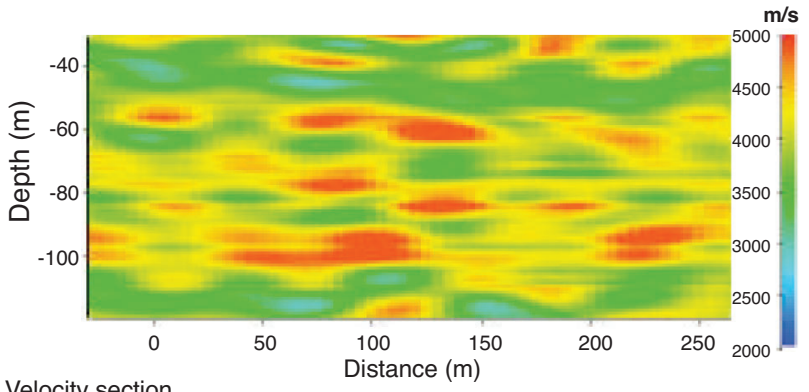

3D block: In line resistivity and velocity seismic sections

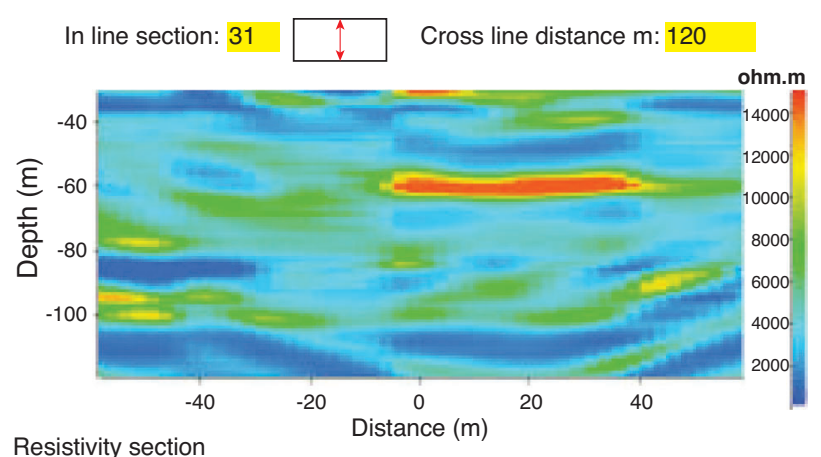

Resistivity section

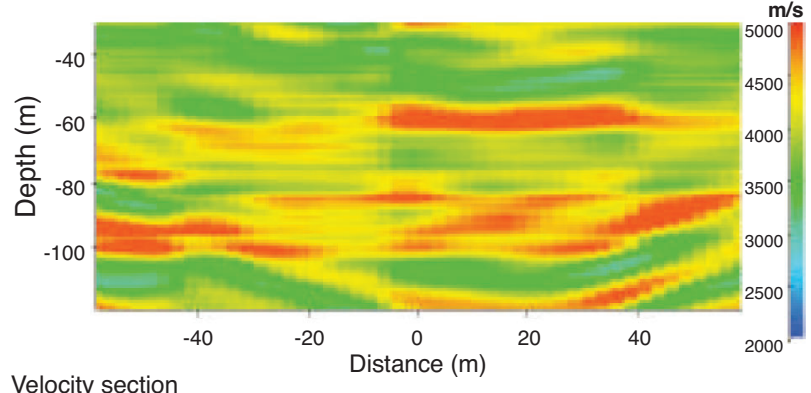

Velocity section

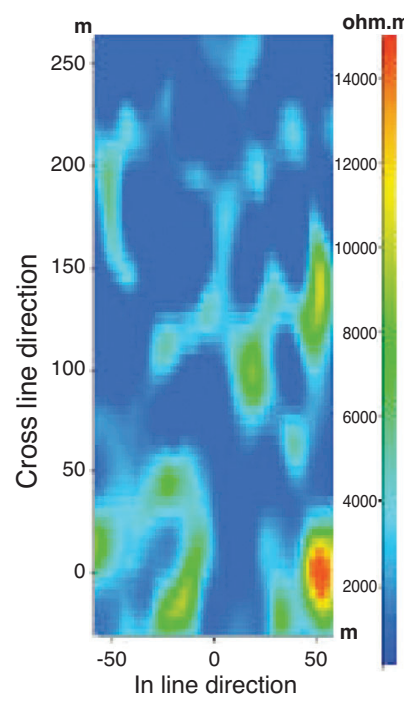

Resistivity map (ohm.m)

Depth

Correlation coefficient between velocity map and resistivity map: 0.820785

Figure 6

From 3D seismic to 3D resistivity.

Examples of pseudo velocity and resistivity depth sections (top left, top right and bottom left).

Comparison between a velocity map and a resistivity map at $87 \mathrm{~m}$ depth (bottom right).

For the location of the seismic lines (Inl 21, Inl 31, Crl 24) see location map (Fig. 2). 
of $87 \mathrm{~m}$, that is within the main productive layer of that aquifer. These seismic pseudo-velocity and pseudo-resistivity sections, extracted from the 3D-block, reveal organized heterogeneities or bodies at the site scale. These heterogeneities mainly appear as horizontal, i.e. deposition-controlled structures, although they may interrupt between two wells and be connected to other bodies through vertical connections.

\subsection{From 3D Resistivity to 3D Porosity}

Archie (1942) has shown empirically that for water-saturated permeable formations, the relation between the true formation resistivity, $R_{t}$, and the resistivity, $R_{w}$, of the water impregnating the formation is given by:

$$
R_{t} / R_{w}=F=\Phi^{-m}
$$

where $F$ is the "resistivity formation factor". $\phi$ is proportional to the formation porosity and $m$ is a "cementation factor", that is a formation characteristic. The $F$ value derived from the resistivity measurement, $R_{t}$, is unaffected by the mineralogical constituents of the formation matrix. Although the "cementation factor" value may vary between 1.3 and 3 according to the formation lithology, an approximate value equal to 2 is generally adopted for well-cemented sedimentary log. Although applicability of Archie's law may be argued a priori for a karstic reservoir, two reasons motivated its adoption. Firstly, the reservoir remains essentially a sedimentary carbonate formation at the seismic resolution scale. Actually, the size of the seismic bin $(2.5 \mathrm{~m}$ in the in line direction, $5 \mathrm{~m}$ in the cross line direction ), and the seismic vertical resolution ranging between 1 and $2 \mathrm{~m}$, lead to an elementary seismic cell volume of $12 \mathrm{~m}^{3}$ at least. Secondly, the volume of the karstic bodies represents only several \% (2 to $3 \%$ ) of the reservoir volume. This volume has been estimated by analyzing borehole images (Audouin, 2007)

For the above two reasons, the previous seismic-derived $3 \mathrm{D}$ resistivity block $\left(R_{t-\text { seis }}\right)$ was converted into a 3D pseudoporosity block, by using the following Archie-law-derived formula with $m=2$ :

$$
\Phi=\sqrt{R_{w} / R_{t}}
$$

with the resistivity of the formation water, $R_{w}$, estimated at 20 ohm.m. Figure 5 (bottom right) shows the porosity log computed from the seismic-derived resistivity $\log , R_{t \text {-seis }}$, at well MP6. The seismic-velocity block and the pseudoporosity block can finally be used to compute a 3D matrix velocity block in order to check the consistency of the previously used conversion functions (Faust and Archie laws). For that purpose, the Wyllie's relationship (1956) is used. For a porous rock of porosity $\phi$, the following relationship can be written between the formation velocity, $V$, the fluid velocity, $V_{f}$, and the matrix velocity:

$$
1 / V=(\phi) / V_{f}+(1-\phi) / V_{m a}
$$

assuming that the seismic contributions of the solid matrix and of the porosity-saturating fluid are in proportion to their respective volume fractions. The matrix velocity values, estimated this way from our seismic velocity and pseudoporosity blocks, are found realistic.

Figure 7 shows examples of matrix velocity and pseudoporosity depth sections. It also shows maps of matrix velocity and pseudo-porosity at a depth of $87 \mathrm{~m}$. The locations of the vertical wells (MP4, MP6, M21, M14, MP5, M18, M10, M04, M07, M09 and M13) and of the 2 highly-deviated wells ( $\mathrm{C} 3$ and $\mathrm{C} 4)$ are reported on that pseudo-porosity map. It is worth noting that the high-porosity layers have high matrix velocities (larger than $6000 \mathrm{~m} / \mathrm{s}$ ). That observation, that also holds horizontally between porosity regions, has to be considered on a qualitative standpoint because of the impact of Archie's law approximation on porosity values.

\section{FROM 3D POROSITY TO 3D RESERVOIR MODEL}

The porosity sections of Figure 7 clearly show high-porosity layers located in the depth intervals 85-87 $\mathrm{m}$ and $110-115 \mathrm{~m}$. The production profiles measured in many wells revealed that these layers actually correspond to the major water feeding levels of wellbores. The porosity map at $87 \mathrm{~m}$ depth shows the extension of the high-porosity bodies and their possible continuity from one well to another. The projected trajectories of the two highly- deviated wells (C3 and C4) are located in two regions where that 87-m deep productive layer is the most porous, hence presumably the most conductive. That porosity distribution was considered as a possible indicator of preferential hydraulic connections between wells. As an example, the high-porosity region linking wells M13 and M21 at that 85-87 m depth interval lets one expect a good hydraulic communication between them. Such a flow connectivity was actually confirmed by well pumping tests and pressure interference measurements. On the contrary, the same porosity map shows that some wells (such as M14) are expected to have a poor hydraulic connection with the surrounding wells.

In order to further analyze the spatial distribution of porous bodies and of presumably-conductive flow paths, different cut-off values were applied to the 3D seismic porosity block. Figure 8 shows several 3D seismic pseudo-porosity blocks, associated with porosity cut-off values of 10 and $30 \%$. The extracted 3D reservoir volume having a porosity smaller than $10 \%$ (Fig. 8, top right) actually represents the largest fraction of that aquifer, i.e. tight carbonates with a low permeability (less than a millidarcy) but nonetheless 

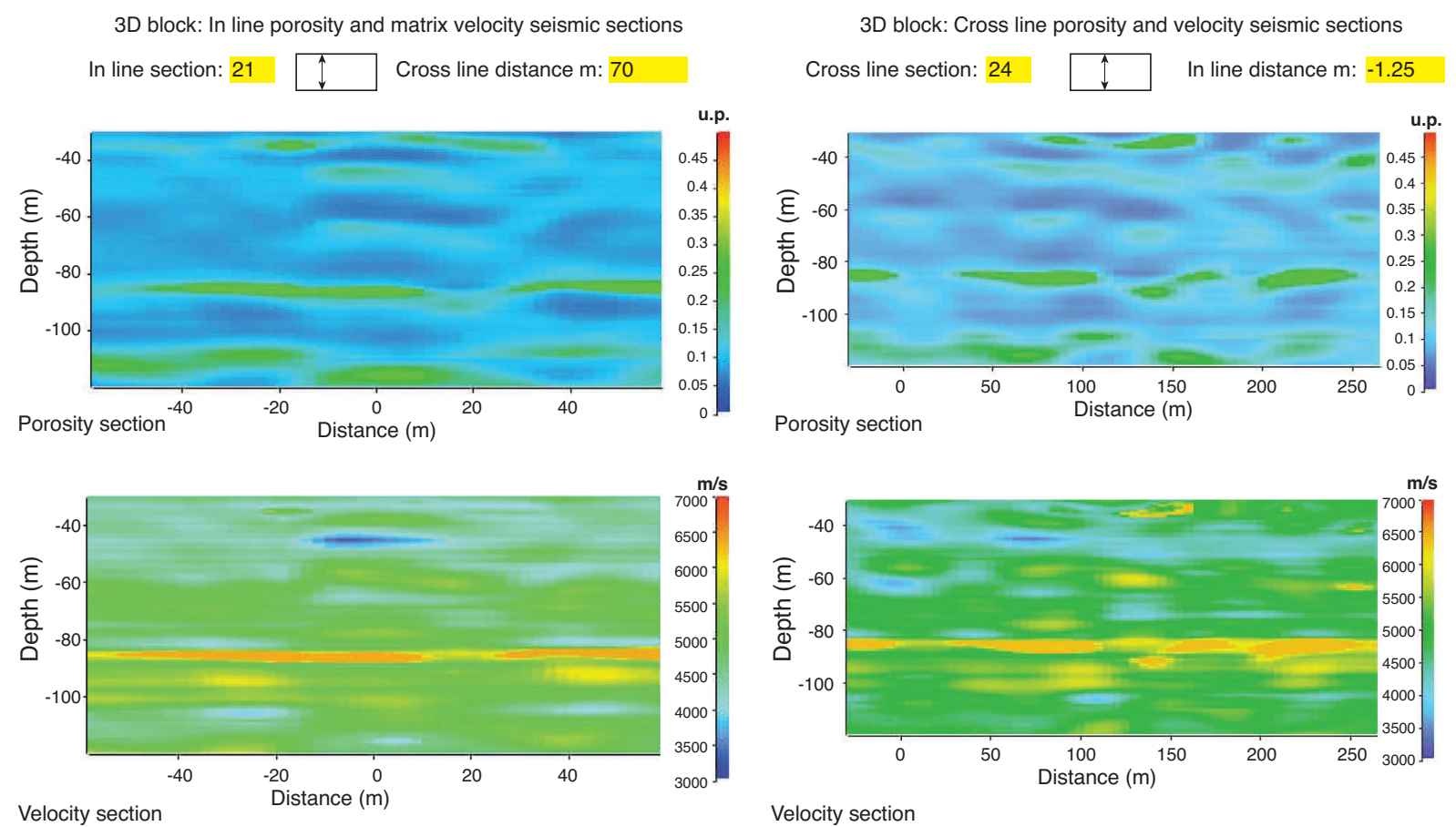

Velocity section
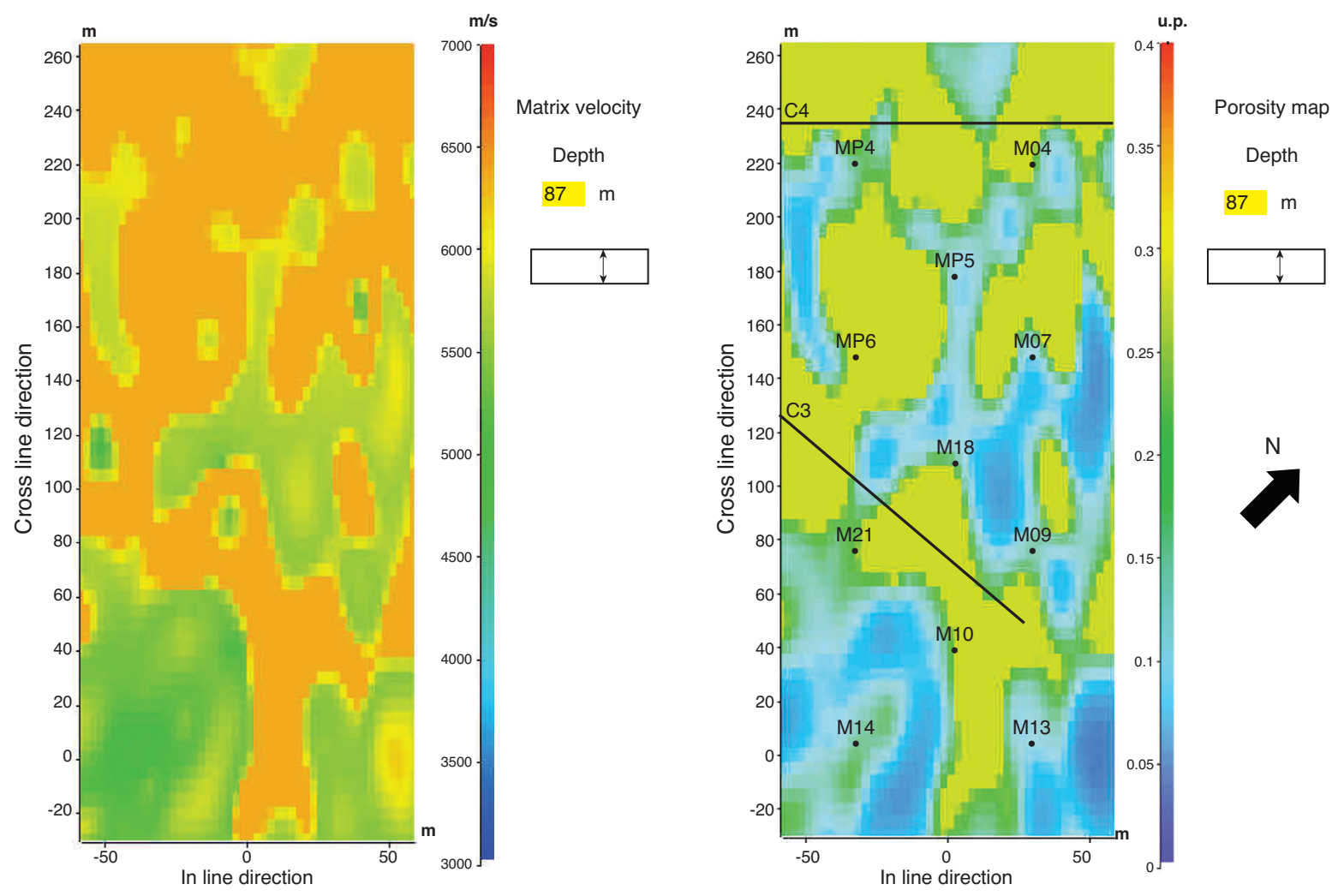

Figure 7

From 3D seismic to 3D porosity.

Top left and right: examples of pseudo matrix velocity and pseudo porosity depth sections.

Bottom left and right: comparison between a matrix velocity map and a porosity map at $87 \mathrm{~m}$ depth. The correlation coefficient between the two maps is 0.816 . Bottom right: porosity map at $87 \mathrm{~m}$ depth and location of the wells.

For the location of the seismic lines (Inl 21, Crl 24) see location map (Fig. 2). 


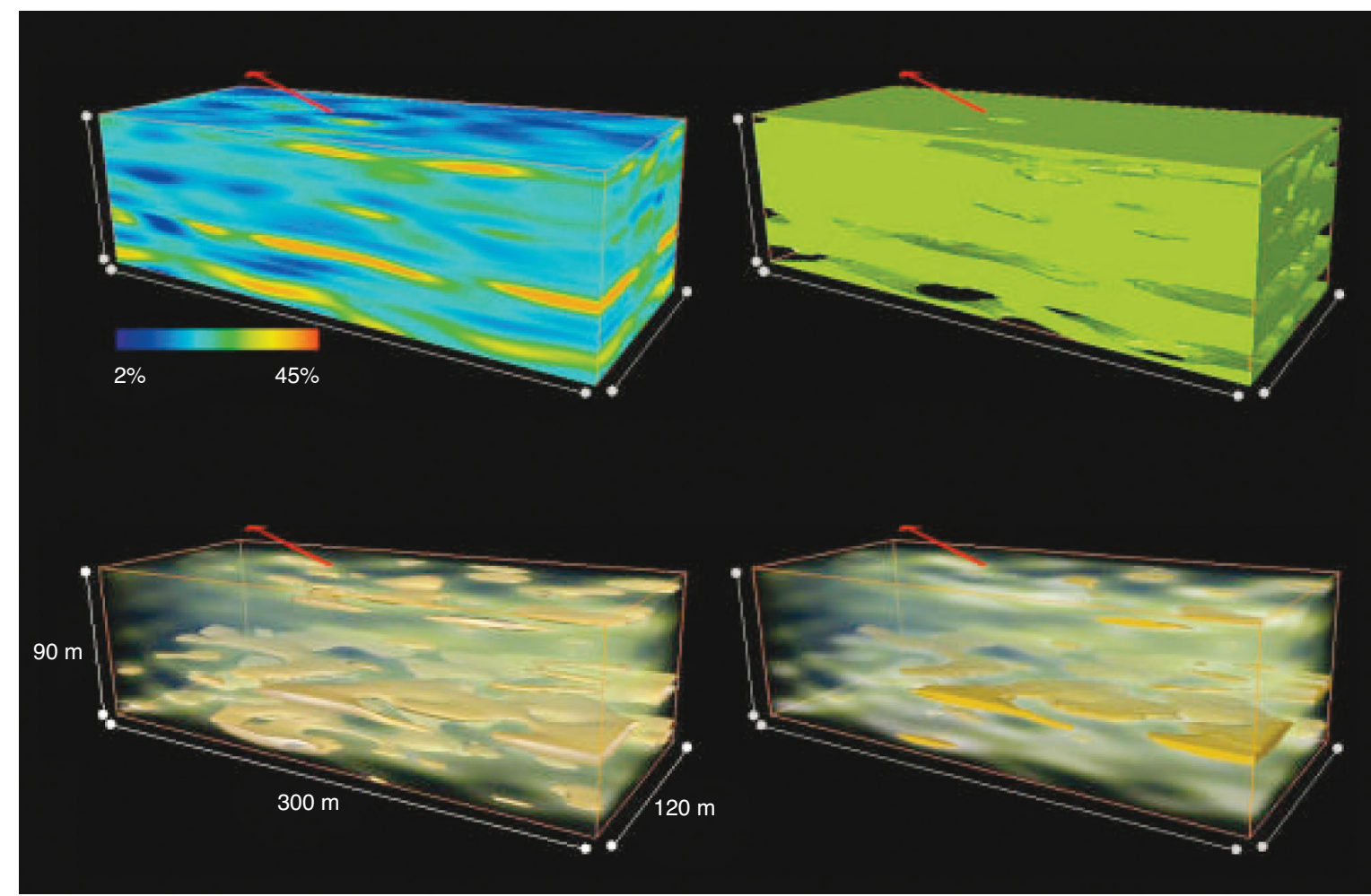

Figure 8

3D seismic pseudo porosity blocks.Detection of karstic bodies, mainly located in the intermediate level (85-87 $\mathrm{m})$. The red arrows indicate the North direction.

Top left: porosity block without any porosity cut off. Top right: compact rocks and shales (bodies having a porosity smaller than $10 \%$ ). Bottom left: porosity block with bodies having a porosity larger than $10 \%$. Bottom right: karstic bodies (bodies having a porosity larger than $30 \%$ ).

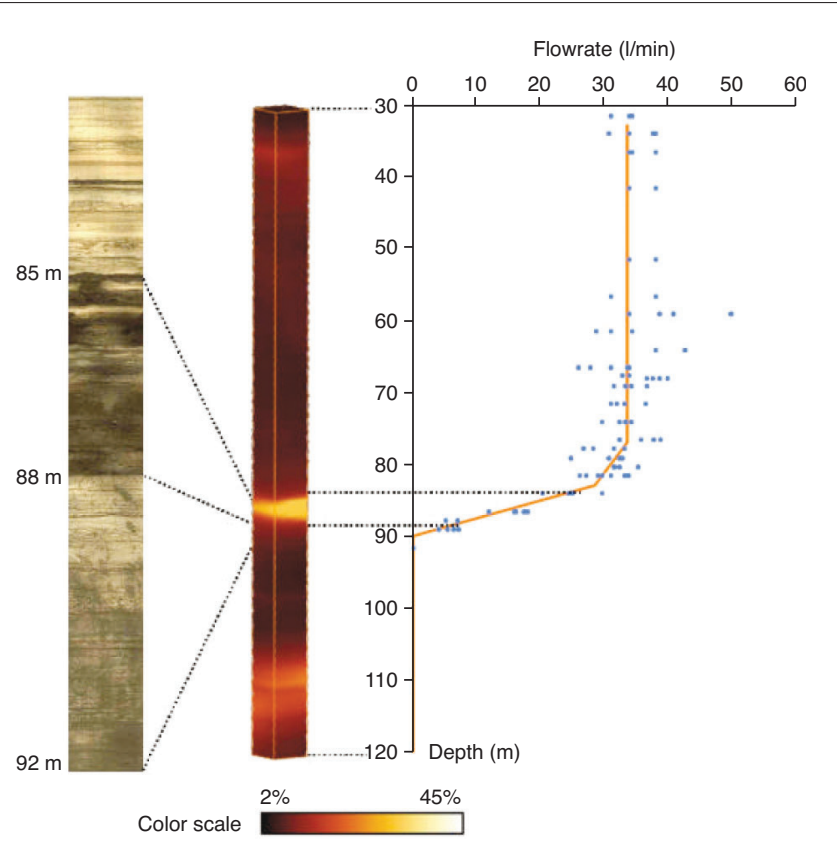

Figure 9

Comparison between geophysical and hydrogeological data at well M21. From left to right: borehole image, 3D seismic block and heatpulse flowmeter. significant storativity. This is consistent with the observation of very sparse and channelized flow paths within that aquifer. We may indeed assume that, within that extracted lowporosity volume, the density of conductive (karstic) bodies is too low to ensure a hydraulic communication between wells, because that the velocity-to-porosity converted block is derived from a high-resolution 3D seismic block, defined at a metric to pluri-metric scale that is significantly less than the well spacing.

The bodies having a porosity larger than $10 \%$ (Fig. 8, bottom left) are mostly distributed within 3 layers, located in the following depth intervals: $35-40 \mathrm{~m}, 85-87 \mathrm{~m}$ and 110-115 m. Finally, a cut-off value of $30 \%$ was applied to the seismic porosity block to evidence the most porous bodies of that aquifer. These highly-porous bodies (Fig. 8, bottom right), mainly located in the intermediate porous layer situated in the 85-87 m depth interval, represent only $2 \%$ of the whole volume of the reservoir block.

Well data, including production profiles, caliper logs and wellbore images confirmed that water feeds the wells via entry points found at the previously-identified depths where high-porosity bodies are mostly found. For example, Figure 9 shows a comparison of hydrogeological and geophysical data at well M21. The geophysical data (part of the 3D pseudo 
porosity seismic block centered on well M21) show at 85-87 $\mathrm{m}$ a high porosity level. At the same depth, this vuggy level is well marked by dark shades on borehole images. Note that this karstic level is sometimes well developed, e.g. $1 \mathrm{~m}$ or more in well M21. The heatpulse flowmeter (HPFM) log conducted under pumping conditions indicates that the M21 productivity is only controlled by the inflow level located at 85-87 m. HPFM conducted on the other wells of the HES show that HES well productivity is mainly controlled by up to three inflow levels: a level around $50 \mathrm{~m}$, one around $90 \mathrm{~m}$ and the last around $110 \mathrm{~m}$ (Audouin et al., 2008; Audouin and Bodin, 2007). Each well intercepts 0, 1 or 2 of these levels. One observes that the high-porosity bodies, as extracted from the 3D-block (Fig. 8, bottom), are not uniformly distributed over the site area, even at the $87 \mathrm{~m}$-depth where they are the most abundant and porous. That observation is again consistent with pumping and interference tests that led to identify several wells with a very low deliverability and insignificant interference with neighboring wells, such as M08, M09 and M14. Reversely, strong interferences for some couples of wells, such as the already-mentioned M13-M21 couple, can be related with the existence of a lowseismic-velocity or high-seismic-porosity body or region between them.

To end with, it becomes very likely that the very-high seismic-porosity zones (larger than 30\%) of the 3D seismic block do correspond to water-productive areas, mainly composed of karstic bodies. That is, the very high resolution seismic survey gave access to a 3D seismic-porosity block that looks quite meaningful in terms of reservoir flow properties. That 3D seismic-porosity block has a sufficiently-high resolution to be used directly as a $3 \mathrm{D}$ geomodel for fluid flow modeling at the site scale. However, although the original seismic information constitutes a valuable deterministic 3D data set, one has to be aware that such seismic-derived porosities still need to be further calibrated quantitatively and in terms of effective flow properties, namely permeabilities, at the model resolution scale under consideration. That calibration can be performed through the flow history match of the multiple pumping and interference tests carried out on that site, and is considered in a next phase of that study.

\section{CONCLUSION}

Different surface seismic surveys have been recorded on an experimental hydrogeological site that has been developed for several years near Poitiers. This paper has shown how 3D seismic imaging can be used to describe the near-surface heterogeneous aquifer. Refraction survey enabled us to obtain a 3D image in depth of a low velocity superficial zone contrasting with the underlying water - bearing carbonates. Factorial kriging was used to filter the small-scale structure in order to evidence the large-scale structures, that are oriented in 2 directions, one main orientation, N90E, and another secondary orientation, N50E.

Reflection survey enabled us to derive a 3D seismic pseudo-velocity block in depth. The vertical resolution is enhanced thanks to deconvolution after depth conversion. The 3D seismic pseudo-velocity block reveals a large heterogeneity of the aquifer reservoir in the horizontal and vertical planes, and confirms the main structural orientations (N90 and N50) identified by the refraction survey. The low-velocity areas are found to correspond to the conductive levels and regions, as identified from well logging and flow interference tests. In order to quantify the porosity variations within that aquifer, the seismic-interval velocities were converted first into resistivity values. For that purpose, the empirical relationship between seismic velocity and true formation resistivity proposed by Faust (1953) was used. Resistivity values were then converted into porosity values, by using the Archie's law (1942). The resulting 3D seismic pseudoporosity block reveals three high-porosity, presumablywater-productive, layers, at depth intervals of 35-40, 85-87 and $110-115 \mathrm{~m}$. The $85-87 \mathrm{~m}$-deep intermediate layer is the most porous one, with bodies having a porosity larger than $30 \%$, that represent the karstic part of the reservoir. That seismic pseudo-porosity distribution appears to be consistent with the available hydrogeological data recorded on the site, as for instance the flow interference taking place via a lowseismic-velocity or high-seismic-porosity zone between wells M13 and M21. Thus, it becomes very likely that the high seismic-porosity zones (larger than 30\%) of the geophysical 3D block correspond to water productive areas. However, the conversion of that pseudo-porosity block into a dynamic-flow-property block was not attempted at that preliminary analysis stage. Actually, these pseudo-porosities remain to be further calibrated, from well data for instance, to be usable as representative porosities for quantitative fluid flow analysis. In addition, the conversion of that isotropic property, porosity, into a directional flow property, such as permeability, is far from bi-univocal a priori. That conversion should be underlain by a conceptual flow model that reflects the reservoir geology and flowing structures under consideration, and the involved parameters be calibrated from well dynamic tests.

To conclude, the very high resolution seismic survey of that near-surface aquifer made possible the construction of a 3D seismic-porosity block that may be regarded as a deterministic high-resolution reservoir model. Although further calibration of porosity values is still required, that 3D seismic-derived information constitutes a valuable constraint for the detailed modelling of the major structures or porous bodies driving flow within that aquifer. Such a history match, constrained by both wellbore and 3D-seismicderived data, is considered as a next phase of the detailed hydro-geological modeling of that heterogeneous karstic/ fractured carbonate aquifer. 


\section{ACKNOWLEDGEMENTS}

We thank the University of Poitiers and IFP for permission to use the field data obtained in a common research project. We thank Fred Delay and Jacques Bodin (Hydrasa), Arnaud Mazurier (ERM) for very useful discussions on various occasions.

\section{REFERENCES}

Archie G.E. (1942) The electrical resistivity log as an aid in determining some reservoir characteristics, Petrol. Technol. 146, 54-62.

Audouin O. (2007) Intégration-inversion de données géologiques et mesures hydrodynamiques in-situ pour le conditionnement d'un modèle 3D d'aquifère calcaire : Site Expérimental Hydrogéologique (SEH) de Poitiers, France, PhD Thesis, Poitiers, 201 p.

Audouin O., Bodin J., Porel G., Bourbiaux B. (2008) Flowpath structure in a limestone aquifer: multi-borehole logging investigations at the hydrogeological experimental site of Poitiers, France, Hydrogeol. J. 16, 939-950.

Audouin O., Bodin J. (2007) Analysis of slug-tests with high-frequency oscillations, J. Hydrol. 334, 282-289.

Bernard S., Delay F., Porel G. (2006) A new method of data inversion for the identification of fractal characteristics and homogenization scale from hydraulic pumping tests in fractured aquifers, J. Hydrol. 328, 647-658.
Bourbiaux B., Callot J.P., Doligez B., Fleury M., Gaumet F., Guiton M., Lenormand R., Mari J.L., Pourpak H. (2007) MultiScale Characterization of a Heterogeneous Aquifer Through the Integration of Geological, Geophysical and Flow Data: A Case Study, Oil Gas Sci. Technol. - Rev. IFP 62, 347-373.

Burbaud-Vergneaud M. (1987) Fracturation et interactions soclecouverture : le seuil du Poitou, PhD Thesis, University of Poitiers, France.

Faust L.Y. (1953) A velocity function including lithologic variation, Geophysics 18, 271-288.

Hagedoorn G.J. (1959) The Plus - Minus method of interpreting seismic refraction sections, Geophys. Prospect. 7, 158-182.

Kaczmaryk A., Delay F. (2007) Interference pumping tests in a fractured limestone (Poitiers - France): Inversion of data by means of dual-medium approaches, J. Hydrol. 337, 133-146.

Mari J.L., Porel G. (2007) 3D seismic imaging of a near - surface heterogeneous aquifer: a case study, Oil Gas Sci. Technol. - Rev IFP 63, 179-201.

Mari J.L., Porel G. (2008) From 3D seismic and resistivity logs to 3D porosity: the case study of a near - surface heterogeneous aquifer, expended abstract D037, 70th EAGE Conference, 9-12 June 2008, Rome.

Wyllie M.R.J., Gregory A.R., Gardner L.W. (1956) Elastic wave velocities in heterogeneous and porous media, Geophysics 21,41-70.

Final manuscript received in September 2008 Published online in February 2009 